Bangladesh Journal of Bioethics 2013; 4(2):1-8

\title{
BIOETHICS AND PATENT LAW: USA, UK AND INDIA. A BIBLIOMETRIC ANALYSIS
}

\author{
Mona Gupta ${ }^{1}$, Divya Srivastava ${ }^{2}$ Arvind Singh Kushwah ${ }^{3}$ \\ 1,2,3 Research Scientist, Scientometric Unit, Division of Publication and Information, \\ Indian Council of Medical Research (HQ.), Ansari Nagar, New Delhi, India, \\ Email: gmona7@gmail.com, drdivta.srivastava@gmail.com, welcomein.arvind@gmail.com
}

\begin{abstract}
This article discusses the view of bioethics in terms of "need of ressearch" and gives more weight to various cultural traditions and their respective moral beliefs. It is argued that this view is implausible for the following three reasons: it renders the disciplinary boundaries of bioethics too flexible and inconsistent with metaphysical commitments of biomedical sciences, it is normatively useless because it approaches cultural phenomena in a predominantly descriptive and selective way, and it tends to justify certain types of discrimination. Compromise on moral matters attracts ambivalent reactions, since it seems at once laudable and deplorable. When a hotly-contested phenomenon like assisted dying is debated, all-or-nothing positions tend to be advanced, with little thought given to the desirability of, or prospects for, compromise. In order to qualify as appropriately principled, the ensuing negotiations require disputants to observe three constraints: they should be suitably reflective, reliable and respectful in their dealings with one another. The product that will result from such a process will also need to split the difference between the warring parties. In assisted dying, I argue that a reduced offence of 'compassionate killing' can achieve this. Clinical research is revolutionizing the practice of medicine in an unprecedented way. Some current legal and ethical concerns evolving from this revolution are addressed, pointing to the emerging concepts in jurisprudence, which regards medical research as an important contribution to patient empowerment, to medical risk management and in managing the resources of a national health system.

While bioethics as a field has concerned itself with methodological issues since the early years, there has been no systematic examination of how ethics is incorporated into research on the ethical, legal and social implications. We aim of better understanding the methods, aims, and approaches to ethics that its researchers employ. We found that the aims of ethics are largely prescriptive and address multiple groups. This is a life concern issue. It is an important issue for researchers, teachers as well as for student. This articles main aim is to provide systematic outline of the complex relationship between bioethics and patent between India, USA and UK. This study suggests that trusting relationships may be more conducive than any particular discussion strategy to facilitating doctor-patient discussions of health care costs. Better public understanding of how medical decisions affect insurer costs and how such costs ultimately affect patients personally will be necessary if discussions about insurer costs are to occur in the clinical encounter. It will give an overview of the bioethics and Patent. The literature survey has indicated that there is no comprehensive work has been done by any researcher on this topic. Therefore the present study would concentrate on the work being carried out by Indian, USA and UK R \& D scientists vis-a-vis Global researchers. Studies aims to map basic human needs such as human health, food and a safe environment, touches on fundamental values, such as human dignity and the genetic integrity of humanity, can raise human rights issues such as access to health and benefits from scientific progress, raises concerns over equitable access to the fruits of new technologies, the consent of those involved in research, and protection of the environment and compare these among India, USA and UK. The research map out many issues and policy communities, but main aspect is the ethical implications of protecting biotechnological inventions through the intellectual property (IP) system. A Bioethicist assists the health care and research community in examining moral issues involved in our understanding of life and death, and resolving ethical dilemmas in medicine and science. This research provides a systematic outline of the complex relationship between bioethics and IP. It will give an overview of bioethics. It sketches core principles in the interaction of IP and bioethics among these three countries.
\end{abstract}


The basic data for the bibliometric analysis has been collected from SCl and for mapping different parameters suitable analytical software eg. SPSS, BibTech Mon is used. The analysis arises questions such as: Does India do enough work in this field. Which country is fastest growth among these?

Introduction: Bioethics is the study of controversial ethics brought about by advances in biology and medicine. Bioethicists are concerned with the ethical questions that arise in the relationships among life sciences, biotechnology, medicine, politics, law, and philosophy. Bioethics is the process of the matters which occur biologically. Bioethics is the compound word with "bios" which represent life or something concerning life with "ethikos" which represent ethics or mores. Both words are traced from Greece. Bioethical studies have developed significantly in the United States. Bioethics purports to deal with the value and ethical issues that have been brought about by the rapid developments of science, technology, and biomedicine during the past fifteen years. Bioethical issues are a serious concern for all of us living in an era of "Life-Manipulation". This is the reason why the new "supra-interdisciplinary" study of "Bioethics" deals with issues relating to all integrated aspects of life's beginning, ending and quality, compared to the too narrow segmentation and ramification trends of traditional academic disciplines dealing with human and life issues separately.

The term Bioethics was coined in 1927 by Fritz Jahr, who "anticipated many of the arguments and discussions now current in biological research involving animals" in an article about the "bioethical imperative," as he called it, regarding the scientific use of animals and plants. Bioethics and animal research: A personal perspective and a note on the contribution of Fritz Jahr. Fritz Jahr's 1927 concept of bioethics. In 1970, the American biochemist Van Rensselaer Potter also used the term with a broader meaning including solidarity towards the biosphere, thus generating a "global ethics," a discipline representing a link between biology, ecology, medicine and human values in order to attain the survival of both human beings and other animal species.

Life science innovations may significantly influence our future. Developments in molecular biology and their applications in health technologies and agriculture have provided new perspectives and created hope for new solutions. The rapid advances in this area accompanied by grant of patent rights on inventions related to, for example DNA sequences, protein sequences, stem cells, and other similar technologies, has prompted examination in international flora of the implications of intellectual property rights and their ethical underpinnings. Bioethical issues are a serious concern for all of us living in an era of "Life-Manipulation".

"Bioethics" is a result of the various human rights movements responding to the de-humanizing phenomena caused by political, economical, technological, and biomedical problems emerging since the end of 1950s mainly in the U.S., Europe and some other places in the world. For example, these various human rights movements are civil liberty movement, woman's rights movement, student movement, and so on.

It is sure that our future direction should be formed in the framework of public participation by having input from the lay-public and the experts in anticipating our "future image" of the world. In this sense, the supra-interdisciplinary study of bioethics and its public policy should be based upon the notion of "Anticipatory Democracy" as well as an action in "Participatory Democracy".

The main objective of the study is to provide a systematic outline of the complex relationship between bioethics and patent. It will give an overview of the bioethics and Patent. It sketches core principles in the interaction of patent and bioethics. It looks at the main sets of issues that are emerging, that are challenging and complex issues. It does not offer any readymade or preferred solutions to today's difficult questions concerning bioethics and patent. But presents a way of clarifying the actual position of patent laws role in issues related to Bioethics. These issues are 
discussed more fully in a background study, which discusses some of the leading cases mentioned briefly in this study bioethics within the law of patents: the scope for judgments about morality in assessments on patentability. The field of bioethics has addressed a broad swath of human inquiry, ranging from debates over the boundaries of life (e.g. abortion, euthanasia), Surrogacy to the allocation of scarce health care resources (e.g. organ donation, health care rationing) to the right to turn down medical care for religious or cultural reasons. Bioethicists often disagree among themselves over the precise limits of their discipline, debating whether the field should concern itself with the ethical evaluation of all questions involving biology and medicine, or only a subset of these questions. Some bioethicists would narrow ethical evaluation only to the morality of medical treatments or technological innovations, and the timing of medical treatment of humans. The literature survey has indicated that there is no comprehensive work has been done by any researcher on this topic. Therefore the present study would concentrate on the work being carried out by Indian R \& D scientists vis-a-vis Global researchers.

About the Database : In view of the importance of bioethics research in the field of human health and well being it becomes important to map out the research activities being carried out by researchers around the world and in India by Indian Scientist. For this purpose we need a searchable consolidated database, but there is no exclusive comprehensive global database on bioethics publications and for Indian efforts also in the field of bioethics. A comprehensive database have been developed for Bibliographical Details of all the research Papers published in USA, UK and India.

Methodology: To carry out the research, efforts were made to collect Global information on research publications in the field of bioethics and Indian research papers published during last 5 years .The data sources have been searched using the search string. MEDLINE and ISA were used to access the trend individually and in comparison to each other.

Global Publications Analysis: The total numbers of papers published during 2005-09 is 2982. During 2009 the number of papers in the field of Bioethics was at its maximum with $51.06 \%$ as shown by the graph. The cumulative publication share in world research output indicated an exponential growth of papers from 8.12 (2005) to 51.06(2009).

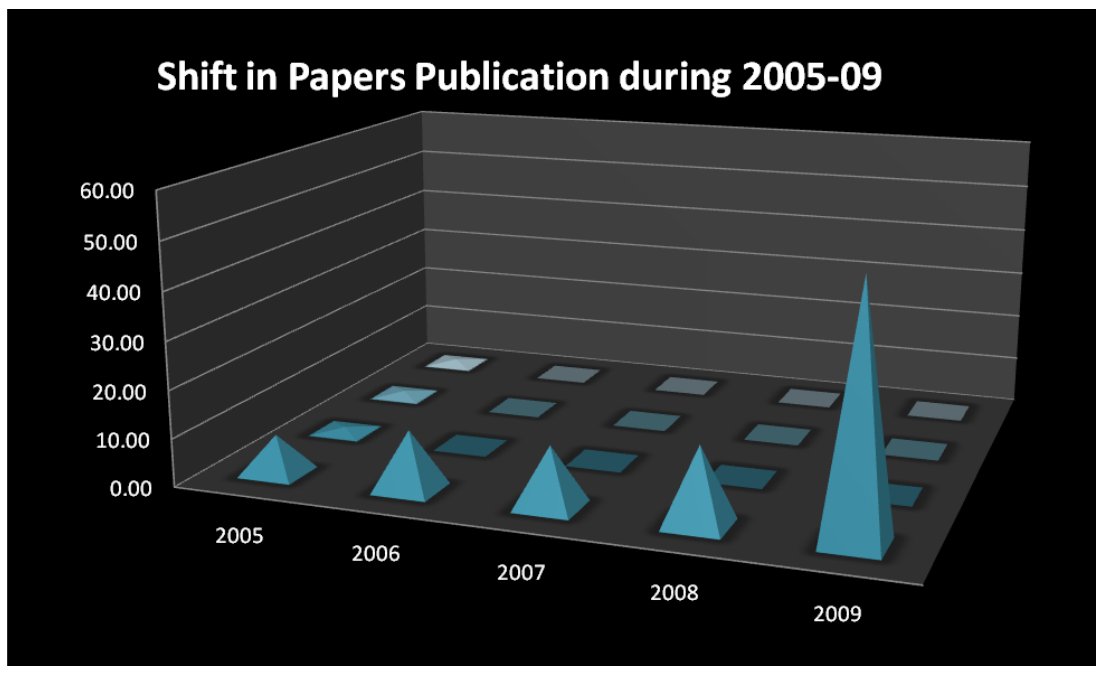

Commitment of Countries towards Bioethics Research: India with its global publications share of $21.66 \%$ computed on the basis of cumulative publications output during the period of 2005-2009. The United States tops the list with global publications share of $63.21 \%$. The United Kingdom global publication share was $15.12 \%$. 


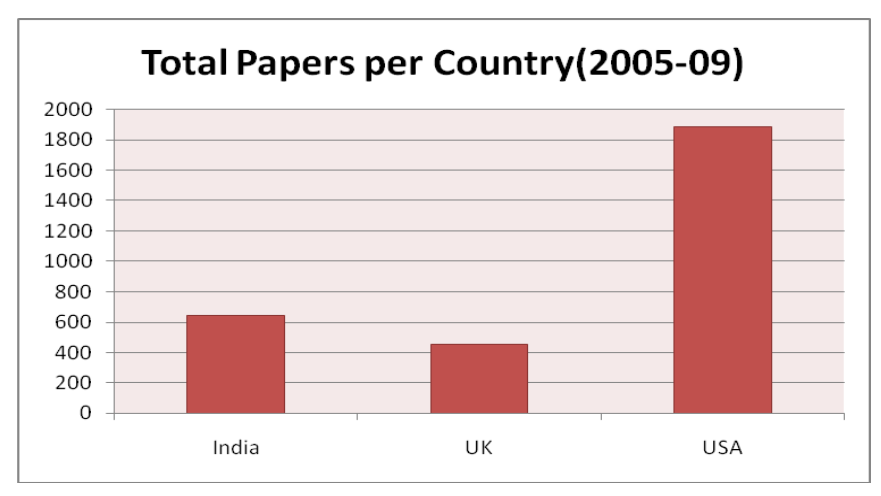

Global Share of USA, UK and India: The average growth rate of countries is from -4.29 to 64.27 during successive years. India's annual growth rate increased from -12.07 to 35.17 . United Kingdom also came up with increased share but its average growth rate decreased from 18.62 to 18.40. In 2006 its growth rate was maximum 23.05\%. United State's Average growth increased, from 4.29 to 64.27 during the period of 5 years. United State is on the top as in the United States more than 25 universities offer degrees in medical ethics. In many instances, the subject also is part of the curriculum in the education of physicians and other health care professionals. Many medical schools include ethics courses that examine topics such as theories of moral decisionmaking and the responsible conduct of medical research. So there is much awareness in Bioethical field compression to other country.

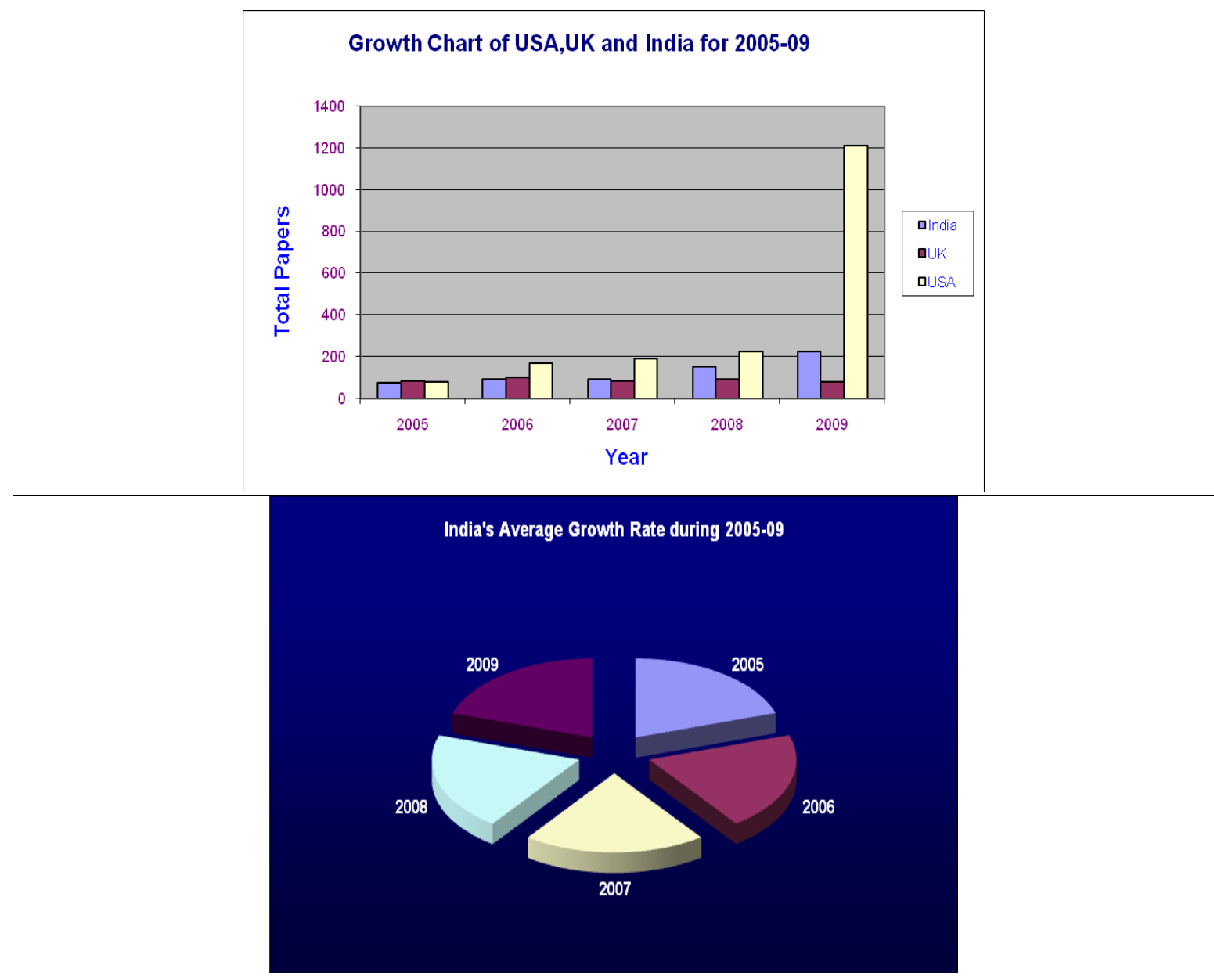


Analysis of Papers on the basis of Subject area (1981-2005): 75 subject areas within Bioethics research were identified, as shown in the list of 'key words'. Areas of health sciences that are the subject of published, peer-reviewed bioethical analysis include:

1. Abortion

2. Animal rights

3. Artificial insemination

4. Artificial life

5. Artificial womb

6. Assisted suicide

7. Biocentrism

8. Biopiracy

9. Biorisk

10. Blood transfusion

11. Body modification

12. Brain-computer interface

13. Chimeras

14. Circumcision

15. Cloning

16. Confidentiality (medical records)

17. Consent

18. Contraception (birth control)

19. Cryonics

20. Disability

21. Eugenics

22. Euthanasia (human, non-human animal)

23. Exorcism

24. Faith Healing

25. Feeding tube

26. Gene theftGene therapy

27. Genetically modified food

28. Genetically modified organism

29. Genomics

30. Great Ape Project

31. Human cloning

32. Human enhancement

33. Human experimentation in the United

States

34. Human genetic engineering

35. latrogenesis

36. Infertility treatments

37. Life extension

38. Life support

39. Lobotomy

40. Medical malpractice

41. Medical research

42. Medical torture

43. Mediation

44. Moral obligation

45. Moral status of animals

46. Nanomedicine

47. Organ donation

48. Organ transplant

49. Pain management

50. Parthenogenesis
51. Patients' Bill of Rights

52. Placebo

53. Political abuse of psychiatry

54. Population control

55. Prescription drugs (prices in the US)

56. Procreative beneficence

57. Professional ethics

58. Psychosurgery

59. Quality of Life (Healthcare)

60. Quaternary prevention

61. Recreational drug use

62. Reproductive rights

63. Reprogenetics

64. Sex reassignment therapy

65. Sperm and eggs (donation)

66. Stem cell research

67. Suicide

68. Surrogacy

69. Three Parent Babies

70. Transhumanism

71. Transplant Trade

72. Vaccination Controversy

73. Xenotransfusion

74. Xenotransplantation

75. Yoga 
Most Productive Journals: There were total 1503 journals publishing a total of 2982 papers during the whole study period (2005-09). There were 593 Journals having one article each. $50 \%$ papers (1490) appeared in a total of 88 journals with an average of approximately 17 papers per journal. The rest of the papers were distributed among a total of 1415 with an average of 1 papers per journal. The top most journal was Blood with 321 papers followed by American Journal of Bioethics (81).

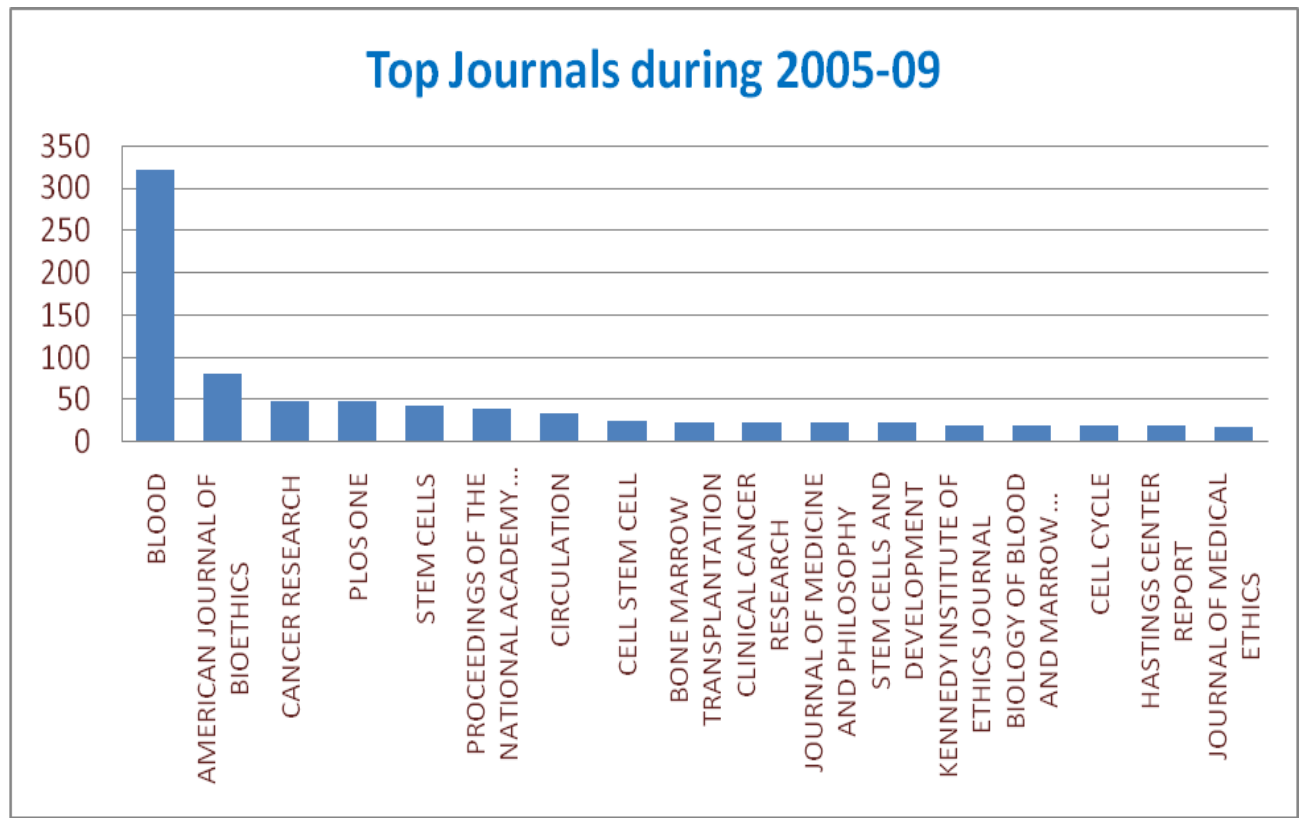

Growth of Journals and Articles: Table below gives the number of Journals and Articles in the area of Bioethics Research. It suggests that both the journals and articles increase exponentially. The number of articles has increased from 243 to 1522 . Also the number of journals has increased from 156 to 566 (2005-09). The figures clearly show that the exponential model fit the empirical data.

Number of Articles and Journals in Bioethics Research

\begin{tabular}{|l|l|l|l|}
\hline & & & \\
Year & No. of Journals & Articles & $\begin{array}{l}\text { Average Growth of } \\
\text { Articles in journals }\end{array}$ \\
\hline $\mathbf{2 0 0 5}$ & 156 & 243 & 64.19753086 \\
\hline $\mathbf{2 0 0 6}$ & 222 & 368 & 60.32608696 \\
\hline $\mathbf{2 0 0 7}$ & 245 & 373 & 65.68364611 \\
\hline $\mathbf{2 0 0 8}$ & 314 & 476 & 65.96638655 \\
\hline $\mathbf{2 0 0 9}$ & 566 & 1522 & 37.18791064 \\
\hline
\end{tabular}




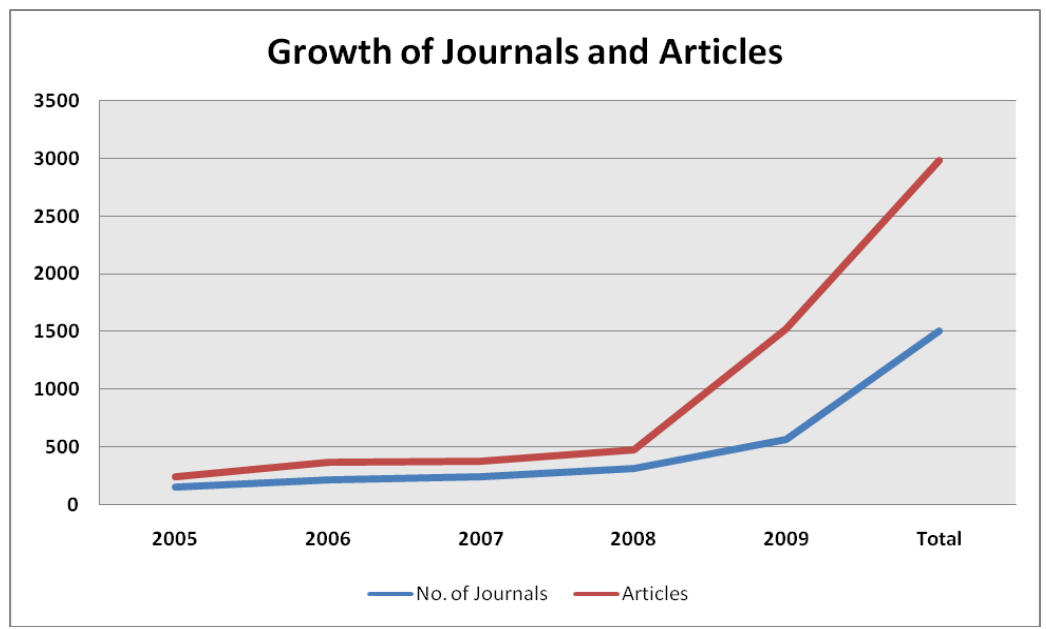

Multiple Authorship: An attempt had been made to study the co-authorship. Table below, gives the data on single and multiple authorship in the area of Bioethics Research for the period 2005-09. Above Figures clearly indicate that the percentage of papers with multiple authors significantly increased, indicating that the research was towards interdisciplinary in nature.

\section{Distribution of Single and $>2$ author Papers}

\begin{tabular}{|l|l|l|}
\hline Year & \# of one Author & \# of $\mathbf{2} \mathbf{2}$ Authors \\
\hline $\mathbf{2 0 0 5}$ & 93 & 150 \\
\hline $\mathbf{2 0 0 6}$ & 186 & 182 \\
\hline $\mathbf{2 0 0 7}$ & 206 & 167 \\
\hline $\mathbf{2 0 0 8}$ & 249 & 227 \\
\hline $\mathbf{2 0 0 9}$ & 1230 & 292 \\
\hline
\end{tabular}

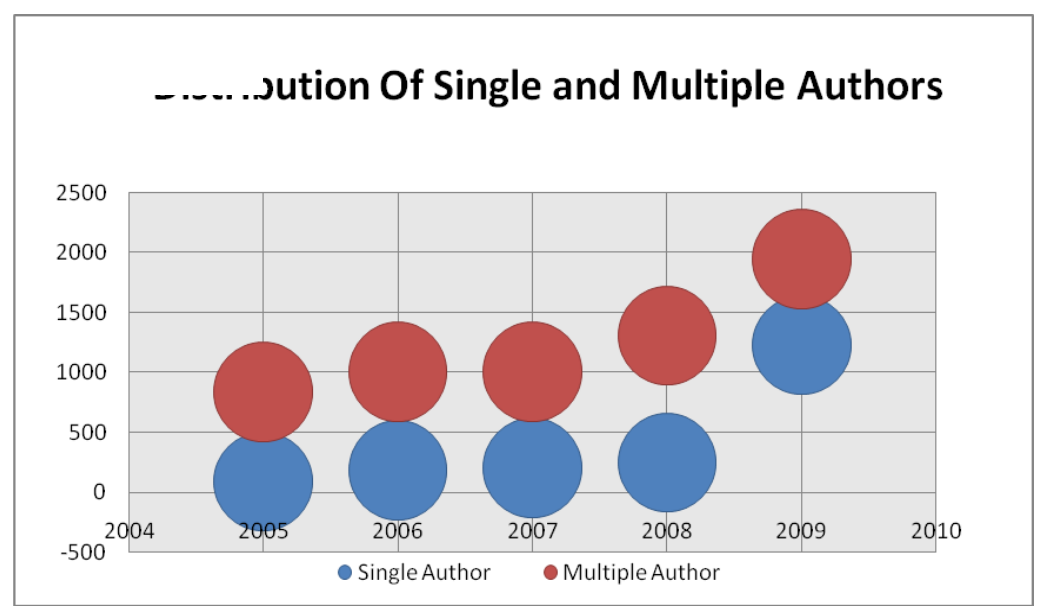

Conclusion: While the roots of bioethics lay in philosophy, today's bioethics requires collaboration among many additional areas of research, including law, medicine, biology, genetics, environmental toxicology, public health, pharmaceuticals, stem cell research, biotechnology, politics, sociology and business. Bioethical dilemmas, once rare, now are commonplace, in part because new medical 
technologies have outpaced our ability to understand their implications. The field of bioethics has addressed a broad swath of human inquiry, ranging from debates over the boundaries of life (e.g. abortion, euthanasia), Surrogacy to the allocation of scarce health care resources (e.g. organ donation, health care rationing) to the right to turn down medical care for religious or cultural reasons. Bioethicists often disagree among themselves over the precise limits of their discipline, debating whether the field should concern itself with the ethical evaluation of all questions involving biology and medicine, or only a subset of these some bioethicists would narrow ethical evaluation only to the morality of medical treatments or technological innovations, and the timing of medical treatment of humans. The literature survey has indicated that there is no comprehensive work has been done by any researcher on this topic. Therefore the present study would concentrate on the work being carried out by Indian R \& D scientists vis-a-vis Global researchers.

\section{References:}

1. De Alba Ulloa. Difficulties of the negotiation process of the Convention for the Protection of Human Rights and Dignity of the Human Being with regard to the application of biology and medicine (and a call for its adhesion)]. J.Gac Med Mex 2012 May-Jun;148(3):307-20.

2. Devaiah $\mathrm{VH}$. Impact of bioethics on patentability of inventions. Indian J Med Ethics 2010 Jan-Mar. 7(1):14-7.

3. Byk C. Patenting human stem cells: an urgent need for a clarification. J Int Bioethique 2008 Sep.19(3):105-19.125-6. 